\title{
ANALISIS KEJADIAN STUNTING PADA BALITA DITINJAU DARI STATUS IMUNISASI DASAR DAN RIWAYAT PENYAKIT INFEKSI
}

\author{
Nurul Khairani ${ }^{1}$, Santoso Ujang Effendi ${ }^{2}$ \\ Program Studi S1 Kesehatan Masyarakat \\ STIKES Tri Mandiri Sakti Bengkulu \\ nurul.sulaksono@gmail.com¹, santos_ue@yahoo.com²
}

\begin{abstract}
The impact of stunting on under five children is developmental disruption, low learning ability, susceptibility to infectious diseases, increased mortality and morbidity, decreased economic capacity and productivity, and the risk of developing non-communicable diseases as an adult. The purpose of this study was to study the relationship between basic immunization status and history of infectious disease with the incidence of stunting in under five children who visited Integrated Health Service Post (Posyandu) in Ratu Samban District, Bengkulu City. This type of research was an Analytical Survey with a Cross Sectional design. The sample was 102 mothers with children aged 12-59 months who visited Posyandu in Ratu Samban District, Bengkulu City. The sampling technique was Accidental Sampling. Data were collected using a questionnaire and anthropometric measurements. Data were analyzed by univariate and bivariate. Bivariate analysis used the Chi-Square statistical test. The results showed that the prevalence of stunting was 31.4\%, 86 mothers (84.3\%) had under five children with complete basic immunization status, and 87 mothers (85.3\%) had under five children with a history of infectious diseases. There was no significant relationship between basic immunization status $(p=1.000)$ and history of infectious disease $(p=0.228)$ with incidence of stunting on toddlers at Posyandu, Ratu Samban District, Bengkulu City. It is hoped that mothers of under five children can provide complete basic immunization to their children and prevent infection in under five children so that the incidence of stunting in under five children can be prevented.
\end{abstract}

Keywords $\quad$ : Basic Immunization Status, History of Infectious Diseases, Incidence of stunting, Under Five Children

\begin{abstract}
ABSTRAK
Dampak stunting pada balita adalah gangguan perkembangan, kemampuan belajar yang rendah, mudah terkena penyakit infeksi, meningkatkan angka kematian dan angka kesakitan, kemampuan ekonomi dan produktivitas menurun, serta berisiko mengalami penyakit tidak menular ketika dewasa. Tujuan penelitian ini adalah untuk mempelajari hubungan antara status imunisasi dasar dan riwayat penyakit infeksi dengan kejadian stunting pada balita yang berkunjung ke Posyandu di Kecamatan Ratu Samban Kota Bengkulu. Jenis penelitian adalah Survei Analitik dengan desain Cross Sectional. Sampel adalah ibu yang memiliki balita berusia 12-59 bulan yang berkunjung ke Posyandu di Kecamatan Ratu Samban Kota Bengkulu sebanyak 102 ibu balita.. Teknik pengambilan sampel adalah Accidental Sampling. Data dikumpulkan dengan menggunakan kuesioner dan pengukuran antropometri. Data dianalisis secara univariat dan bivariat. Analisis bivariat menggunakan uji statistik Chi-Square $\left(\chi^{2}\right)$. Hasil penelitian menunjukkan bahwa prevalensi kejadian stunting sebesar $31,4 \%, 86$ ibu $(84,3 \%)$ memiliki balita dengan status imunisasi dasar lengkap, dan 87 ibu $(85,3 \%)$ memiliki balita dengan riwayat penyakit infeksi. Tidak ada hubungan antara status imunisasi dasar $(\mathrm{p}=1,000)$ dan riwayat penyakit infeksi $(p=0,228)$ dengan kejadian stunting pada balita di Posyandu Kecamatan Ratu Samban Kota Bengkulu. Diharapkan kepada ibu balita agar dapat memberikan imunisasi dasar lengkap kepada balitanya dan mencegah infeksi pada balita sehingga kejadian stunting pada balita dapat dicegah.
\end{abstract}

Kata Kunci : Balita, Kejadian Stunting, Riwayat Penyakit Infeksi, Status Imunisasi Dasar 


\section{PENDAHULUAN}

Stunting adalah kondisi retardasi pertumbuhan yang terjadi pada 1.000 hari pertama kehidupan. Kehidupan awal anak sangat menentukan tumbuh kembang anak selanjutnya (de Onis \& Branca, 2016). Sebagian besar kejadian gagal tumbuh terjadi dalam dua tahun pertama kehidupan. Stunting pada masa anak-anak adalah salah satu hambatan yang paling signifikan bagi perkembangan manusia. Secara global, sekitar 162 juta anak berusia di bawah 5 tahun mengalami kejadian stunting (WHO, 2020).

Dampak stunting bersifat tidak dapat diperbaiki setelah anak berusia dua tahun (Cusick, \& Georgieff, 2012). Dampak stunting pada balita adalah gangguan perkembangan, kemampuan belajar yang rendah, mudah terkena penyakit infeksi, meningkatkan angka kematian dan angka kesakitan, kemampuan ekonomi dan produktivitas menurun, serta berisiko mengalami penyakit tidak menular ketika dewasa (Stewart et al., 2013).

Prevalensi stunting nasional pada tahun 2013 adalah $37,2 \% \quad(18,0 \%$ sangat pendek dan 19,2\% pendek). Prevalensi sangat pendek sebesar $18,8 \%$ pada tahun 2007 dan 18,5\% pada tahun 2010. Prevalensi pendek meningkat dari $18,0 \%$ pada tahun 2007 menjadi 19,2\% pada tahun 2013 (Kementerian Kesehatan RI, 2013).

Prevalensi kejadian stunting pada balita di Provinsi Bengkulu sebesar 36,0\% (Departemen Kesehatan RI, 2008). Prevalensi kejadian stunting pada balita di Provinsi Bengkulu pada tahun 2010 sebesar 31,6\% (Kementerian Kesehatan RI, 2010). Pada tahun 2013, Provinsi Bengkulu merupakan salah satu provinsi yang memiliki prevalensi stunting di atas prevalensi stunting nasional (Kementerian Kesehatan RI, 2013). Berdasarkan hasil survei Pemantauan Status Gizi (PSG) yang dilakukan oleh Dinas Kesehatan Propinsi Bengkulu pada tahun 2015, prevalensi stunting di Provinsi Bengkulu sebesar $29,0 \%$ (Dinas Kesehatan Provinsi
Bengkulu, 2015) yang menurut standar WHO (1997) merupakan masalah kesehatan masyarakat dalam kategori sedang.

Imunisasi adalah proses yang membuat kebal terhadap penyakit. Imunisasi adalah salah satu pengobatan yang dilakukan untuk mengurangi mortalitas dan morbiditas pada anak. Imunisasi juga dapat menjaga status gizi anak dan mencegah malnutrisi (Misra at al, 2015). Hasil penelitian Agustia, Rahman, \& Hermiyanty (2018) menunjukkan bahwa imunisasi yang tidak lengkap merupakan faktor risiko kejadian stunting pada balita usia 12-59 bulan di wilayah Tambang Poboya Kota Palu.

Penyakit infeksi merupakan faktor penyebab langsung kejadian stunting. Penyakit infeksi mengakibatkan nafsu makan menjadi berkurang sehingga asupan makanan menjadi berkurang. Di samping itu, zat gizi yang dikonsumsi tidak digunakan untuk pertumbuhan tubuh, tetapi akan dialihkan oleh tubuh untuk mengatasi infeksi. Ketika sakit, tubuh akan membutuhkan jumlah zat gizi yang lebih besar untuk melawan penyakitnya (Darmadi, 2008). Swathma et al (2016) mengungkapkan bahwa balita yang memiliki riwayat penyakit infeksi akan berisiko mengalami kejadian stunting sebesar 2,979 kali jika dibandingkan dengan balita yang tidak mengalami kejadian stunting.

Menurut data Dinas Kesehatan Kota Bengkulu (2014), prevalensi kejadian stunting pada balita tahun 2013 sebesar 21,07\%. Hasil survei Pemantauan Status Gizi (PSG) tahun 2015 menunjukkan bahwa prevalensi stunting pada balita di Kota Bengkulu sebesar 14,8\%. Pada tahun 2014, prevalensi stunting pada balita di Kecamatan Ratu Samban Kota Bengkulu tertinggi jika dibandingkan dengan 9 kecamatan yang ada di Kota Bengkulu, yaitu sebesar 20,33\%. Prevalensi ini di atas prevalensi Kota Bengkulu yang hanya sebesar 7,07\% (Dinas Kesehatan Provinsi, 2015). Jika prevalensi kejadian stunting di 
atas 20,0\%, maka masih menjadi masalah kesehatan masyarakat. Berdasarkan standar WHO (1997), prevalensi kejadian stunting di Kecamatan Ratu Samban masih masuk dalam kategori sedang. Data prevalensi stunting pada balita di Kecamatan Ratu Samban Kota Bengkulu pada tahun 2015 tidak tersedia di Dinas Kesehatan Kota karena PSG untuk Kota Bengkulu per kecamatan dan wilayah kerja Puskesmas tidak dilakukan.

Penelitian sebelumnya tentang "Analisis Kejadian Stunting pada Balita Ditinjau dari Status Imunisasi Dasar dan Riwayat Penyakit Infeksi di Posyandu Kecamatan Ratu Samban Kota Bengkulu" belum pernah dilakukan sebelumnya. Oleh karena itu, tujuan penelitian ini adalah untuk mempelajari hubungan antara status imunisasi dasar dan riwayat penyakit infeksi dengan kejadian stunting pada balita di Posyandu di Kecamatan Ratu Samban Kota Bengkulu.

\section{METODE}

Jenis penelitian adalah Survey Analitik dan desainnya adalah Cross Sectional. Pengambilan data di lapangan dilakukan pada tanggal 05-22 Juni 2017. Penelitian dilakukan di Posyandu di Kecamatan Ratu Samban yang berada di dua wilayah kerja Puskesmas, yaitu Puskesmas Anggut Atas dan Puskesmas Penurunan. Populasi penelitian adalah seluruh ibu yang memiliki balita usia 12-59 bulan yang berkunjung ke Posyandu di Kecamatan Ratu Samban Kota Bengkulu tahun 2015 berjumlah 1895 balita. Sampel dalam penelitian ini adalah ibu yang memiliki balita usia 12-59 bulan yang berkunjung ke Posyandu di Kecamatan Ratu Samban Kota Bengkulu dengan jumlah 102 ibu balita. Teknik pengambilan sampel dalam penelitian ini adalah Accidental Sampling.

Data terdiri dari data primer dan data sekunder. Data primer terdiri dari status imunisasi dasar, riwayat penyakit infeksi, dan status gizi stunting. Data primer didapatkan melalui wawancara langsung terhadap sampel, melihat buku KMS/KIA, dan melakukan pengukuran tinggi badan, serta umur balita. Data sekunder diperoleh dari Dinas Kesehatan Provinsi dan Kota Bengkulu, Puskesmas Anggut Atas dan Puskesmas Penurunan. Data dianalisis secara univariat dan bivariat. Analisis bivariat menggunakan uji statistik Chi-Square $\left(\chi^{2}\right)$. Data diolah dengan menggunakan program SPSS 18.0.

\section{HASIL}

\section{Analisis Univariat}

Analisis univariat bertujuan untuk mengetahui distribusi frekuensi variabel bebas (status imunisasi dasar dan riwayat penyakit infeksi) dan variabel terikat (kejadian stunting). Hasilnya adalah sebagai berikut :

Tabel 1. Distribusi Frekuensi Status Imunisasi Dasar pada Balita di Posyandu Kecamatan Ratu Samban Kota Bengkulu

\begin{tabular}{|c|c|c|c|}
\hline No. & Status Imunisasi Dasar & Frekuensi & Persentase (\%) \\
\hline 1. & Tidak Lengkap & 16 & 15,7 \\
\hline 2. & Lengkap & 86 & 84,3 \\
\hline & Jumlah & 102 & $\mathbf{1 0 0 , 0}$ \\
\hline
\end{tabular}

Keterangan : Data Primer, 2017

Berdasarkan Tabel 1 diketahui bahwa dari 102 ibu yang memiliki balita di Posyandu Kecamatan Ratu Samban Kota Bengkulu, terdapat 16 ibu (15,7\%) memiliki balita dengan status imunisasi dasar tidak lengkap dan 86 ibu (84,3\%) memiliki balita dengan status imunisasi dasar lengkap. 
Tabel 2. Distribusi Frekuensi Riwayat Penyakit Infeksi pada Balita di Posyandu Kecamatan Ratu Samban Kota Bengkulu

\begin{tabular}{ccccc}
\hline No. & & Penyakit Infeksi & Frekuensi & Persentase (\%) \\
\hline 1 & Ada & & 87 & 85,3 \\
2 & Tidak Ada & & 15 & 14,7 \\
\hline & & Total & $\mathbf{1 0 2}$ & $\mathbf{1 0 0 , 0}$ \\
\hline
\end{tabular}

Keterangan : Data Primer, 2017

Berdasarkan Tabel 2 diketahui bahwa dari 102 ibu yang memiliki balita di Posyandu Kecamatan Ratu Samban Kota Bengkulu, terdapat 87 ibu $(85,3 \%)$ memiliki balita yang memiliki riwayat penyakit infeksi dan 15 ibu $(14,7 \%)$ memiliki balita yang tidak memiliki riwayat penyakit infeksi di Posyandu Kecamatan Ratu Samban Kota Bengkulu.

Tabel 3. Distribusi Frekuensi Kejadian Stunting pada Balita di Posyandu Kecamatan Ratu Samban Kota Bengkulu

\begin{tabular}{ccccc}
\hline No. & \multicolumn{2}{c}{ Kejadian Stunting } & Frekuensi & Persentase (\%) \\
\hline 1 & Stunting & & 32 & 31,4 \\
2 & Tidak Stunting & & 70 & 68,6 \\
\hline & & Total & $\mathbf{1 0 2}$ & $\mathbf{1 0 0 , 0}$ \\
\hline
\end{tabular}

Keterangan : Data Primer, 2017

Berdasarkan Tabel 3 diketahui bahwa dari 102 ibu yang memiliki balita di Posyandu Kecamatan Ratu Samban Kota Bengkulu, terdapat 32 ibu $(31,4 \%)$ memiliki balita yang mengalami kejadian stunting dan 70 ibu $(68,6 \%)$ memiliki balita yang tidak mengalami kejadian stunting di Posyandu Kecamatan Ratu Samban Kota Bengkulu.

\section{Analisis Bivariat}

Analisis bivariat bertujuan untuk mempelajari hubungan antara variabel bebas (status imunisasi dasar dan riwayat penyakit infeksi) dengan variabel terikat (kejadian stunting). Hasilnya adalah sebagai berikut :

Tabel 4. Tabulasi Silang antara Status Imunisasi Dasar dengan Kejadian Stunting pada Balita di Posyandu Kecamatan Ratu Samban Kota Bengkulu

\begin{tabular}{|c|c|c|c|c|c|c|c|c|}
\hline \multirow{3}{*}{ Status Imunisasi Dasar } & \multicolumn{4}{|c|}{ Kejadian Stunting } & \multirow{2}{*}{\multicolumn{2}{|c|}{ Total }} & \multirow{3}{*}{$\chi^{2}$} & \multirow{3}{*}{$\mathbf{p}$} \\
\hline & \multicolumn{2}{|c|}{ Stunting } & \multicolumn{2}{|c|}{ Tidak Stunting } & & & & \\
\hline & $\mathbf{F}$ & $\%$ & $\mathbf{F}$ & $\%$ & $\mathbf{F}$ & $\%$ & & \\
\hline Tidak Lengkap & 5 & 31,2 & 11 & 68,8 & 16 & 100,0 & & \\
\hline Lengkap & 27 & 31,4 & 59 & 68,6 & 86 & 100,0 & 0,000 & 1,000 \\
\hline Total & 32 & 31,4 & 70 & 68,6 & 102 & 100,0 & & \\
\hline
\end{tabular}

Keterangan : Data Primer, 2019

Berdasarkan Tabel 5 dapat diketahui bahwa dari 16 ibu yang memiliki balita dengan status imunisasi dasar tidak lengkap, terdapat $5 \mathrm{ibu}$ yang memiliki balita yang mengalami kejadian stunting dan 11 ibu yang memiliki balita yang tidak mengalami kejadian stunting. Dari 86 ibu yang memiliki balita dengan status imunisasi dasar lengkap, terdapat $27 \mathrm{ibu}$ yang memiliki balita yang mengalami kejadian stunting dan 59 ibu yang memiliki balita yang tidak mengalami kejadian stunting.

Untuk mengetahui hubungan antara status imunisasi dasar dengan kejadian stunting pada balita di Posyandu Kecamatan Ratu Samban Kota Bengkulu digunakan uji Chi-Square (Continuity Correction Test). Hasil uji Continuity Correction test menunjukkan bahwa nilai 
exact.sig $(p)=1,000$. Jadi tidak ada hubungan yang signifikan antara status imunisasi dasar balita dengan kejadian stunting di Posyandu Kecamatan Ratu Samban Kota Bengkulu.

Tabel 4. Tabulasi Silang antara Riwayat Penyakit Infeksi dengan Kejadian Stunting pada Balita di Posyandu Kecamatan Ratu Samban Kota Bengkulu

\begin{tabular}{|c|c|c|c|c|c|c|c|c|}
\hline \multirow{3}{*}{ Riwayat Penyakit Infeksi } & \multicolumn{4}{|c|}{ Kejadian Stunting } & \multirow{2}{*}{\multicolumn{2}{|c|}{ Total }} & \multirow{3}{*}{$\chi^{2}$} & \multirow{3}{*}{$\mathbf{p}$} \\
\hline & \multicolumn{2}{|c|}{ Stunting } & \multicolumn{2}{|c|}{ Tidak Stunting } & & & & \\
\hline & $\mathbf{F}$ & $\%$ & $\mathbf{F}$ & $\%$ & $\mathbf{F}$ & $\%$ & & \\
\hline Ada & 25 & 28,7 & 62 & 71,3 & 87 & 100,0 & & \\
\hline Tidak Ada & 7 & 46,7 & 8 & 53,3 & 15 & 100,0 & - & 0,228 \\
\hline Total & 32 & 31,4 & 70 & 68,6 & 102 & 100,0 & & \\
\hline
\end{tabular}

Keterangan : Data Primer, 2017

Berdasarkan Tabel 4 dapat diketahui bahwa dari 87 ibu yang memiliki balita dengan riwayat penyakit infeksi, terdapat 25 ibu yang memiliki balita yang mengalami kejadian stunting dan 62 ibu yang memiliki balita yang tidak mengalami kejadian stunting. Dari $15 \mathrm{ibu}$ yang memiliki balita dengan tidak ada riwayat penyakit infeksi, terdapat $7 \mathrm{ibu}$ yang memiliki balita yang mengalami kejadian stunting dan 8 ibu yang memiliki balita yang tidak mengalami kejadian stunting.

Untuk mengetahui hubungan antara riwayat penyakit infeksi dengan kejadian stunting pada balita di Posyandu Kecamatan Ratu Samban Kota Bengkulu digunakan uji Chi-Square (Fisher Exact Test). Hasil uji Fisher Exact test menunjukkan bahwa nilai exact.sig $(\mathrm{p})=$ 0,228. Jadi tidak ada hubungan yang signifikan antara riwayat penyakit infeksi dengan kejadian stunting di Posyandu Kecamatan Ratu Samban Kota Bengkulu.

\section{PEMBAHASAN}

\section{Hubungan antara Status Imunisasi Dasar dengan Kejadian Stunting pada Balita}

Hasil penelitian menunjukkan bahwa balita yang memiliki status imunisasi dasar lengkap lebih banyak yang tidak mengalami kejadian stunting jika dibandingkan dengan balita yang memiliki status imunisasi dasar yang tidak lengkap. Berdasarkan hasil analisis bivariat menunjukkan bahwa status imunisasi dasar tidak berhubungan signifikan dengan kejadian stunting pada balita di Posyandu Kecamatan Ratu Samban Kota Bengkulu. Artinya status imunisasi dasar tidak menentukan kejadian stunting pada balita di Posyandu Kecamatan Ratu Samban Kota Bengkulu.

Hasil penelitian ini tidak sejalan dengan hasil penelitian Agustia, Rahman, \& Hermiyanty (2018) yang menunjukkan bahwa imunisasi yang tidak lengkap merupakan faktor risiko kejadian stunting pada balita usia $12-59$ bulan di wilayah Tambang Poboya Kota Palu. Riwayat pemberian imunisasi tidak berhubungan dengan kejadian stunting pada anak usia 24-59 bulan di Kecamatan Ratahan Kabupaten Minahasa Tenggara (Kasim, Malonda, \& Amisi, 2019).

Hasil penelitian ini tidak sejalan dengan teori yang menyatakan bahwa vaksin dapat menurunkan risiko kematian pada anak. Pemberian vaksin secara dini dapat mengurangi kejadian stunting. Jika pemberian vaksin terlambat, maka dapat meningkatkan kejadian stunting (Berendsen et al, 2016).

Hasil penelitian ini sejalan dengan hasil penelitian Fajariyah \& Hidajah (2020) yang menunjukkan bahwa status imunisasi tidak memiliki hubungan dengan kejadian stunting pada anak usia 2-5 tahun di Indonesia. Status imunisasi tidak berhubungan dengan kejadian stunting pada balita di Desa Kedung Jati (Anmaru \& Laksono, 2019). 


\section{Hubungan antara Riwayat Penyakit Infeksi dengan Kejadian Stunting pada Balita}

Hasil penelitian menunjukkan bahwa jumlah anak yang memiliki riwayat penyakit infeksi dan mengalami kejadian stunting lebih banyak jika dibandingkan dengan anak yang tidak memiliki riwayat penyakit infeksi. Berdasarkan hasil analisis bivariat menunjukkan bahwa riwayat penyakit infeksi tidak berhubungan signifikan dengan kejadian stunting pada balita di Posyandu Kecamatan Ratu Samban Kota Bengkulu. Artinya riwayat penyakit infeksi tidak menentukan kejadian stunting pada balita di Posyandu Kecamatan Ratu Samban Kota Bengkulu.

Hasil penelitian ini tidak sejalan dengan hasil penelitian Agustia, Rahman, \& Hermiyanty (2018) yang menunjukkan bahwa riwayat penyakit infeksi merupakan faktor risiko kejadian stunting pada balita usia 12-59 bulan di wilayah Tambang Poboya Kota Palu. Swathma et al (2016) mengungkapkan bahwa balita yang memiliki riwayat penyakit infeksi akan berisiko mengalami kejadian stunting sebesar 2,979 kali jika dibandingkan dengan balita yang tidak stunting.

Hasil penelitian tidak sejalan dengan teori yang dikemukakan oleh Darmadi (2008) bahwa penyakit infeksi merupakan faktor penyebab langsung kejadian stunting. Penyakit infeksi mengakibatkan nafsu makan menjadi berkurang sehingga asupan makanan menjadi berkurang. Di samping itu, zat gizi yang dikonsumsi tidak digunakan untuk pertumbuhan tubuh, tetapi akan dialihkan oleh tubuh untuk mengatasi infeksi. Ketika sakit, tubuh akan membutuhkan jumlah zat gizi yang lebih besar untuk melawan penyakitnya.

Hasil penelitian ini tidak sejalan dengan hasil penelitian sebelumnya bisa disebabkan karena adanya keterbatasan dalam penelitian ini. Untuk mengetahui riwayat penyakit infeksi untuk tiga bulan terakhir, data yang diperoleh hanya berdasarkan hasil wawancara dengan ibu balita, bukan berdasarkan data dari
Puskesmas atau diagnosis dokter. Berdasarkan hasil wawancara dengan para responden, penyakit yang sering dialami oleh balita adalah diare dan infeksi saluran pernapasan akut (ISPA).

\section{KESIMPULAN}

Hasil penelitian menunjukkan bahwa prevalensi kejadian stunting sebesar 31,4\%, 86 ibu $(84,3 \%)$ memiliki balita dengan status imunisasi dasar lengkap, dan 87 ibu $(85,3 \%)$ memiliki balita dengan riwayat penyakit infeksi.. Tidak ada hubungan antara status imunisasi dasar dan riwayat penyakit infeksi dengan kejadian stunting pada balita di Posyandu Kecamatan Ratu Samban Kota Bengkulu. Diharapkan kepada ibu balita agar dapat memberikan imunisasi dasar lengkap kepada balitanya dan mencegah infeksi pada balita sehingga kejadian stunting pada balita dapat dicegah.

\section{DAFTAR PUSTAKA}

Agustia, R., Rahman, N., \& Hermiyanty, (2018). Faktor Risiko Kejadian Stunting pada Balita Usia 12-59 Bulan di Wilayah Tambang Poboya Kota Palu. Ghidza Jurnal Gizi dan Kesehatan, 2 (2) : 59-62.

Anmaru, Y. Y. R., \& Laksono, B. (2019). The Influencing Factor Analysis of Stunting Incidence in Children Aged 24-59 Months at Kedung Jati Village. Public Health Perspectives Journal, 4 (2) : 116 - 121.

Berendsen, M. L. T., Smits, J., Netea, M. G., \& Van Der Ven, A. (2016). Non-Specific Effects of Vaccines and Stunting: Timing Maybe Essential. EBio Medicine, 8, 341348.Https://doi.org/10.1016/j.ebiom .2016.05.010.

Cusick, S.E.; Georgieff, M.K. (2012). Nutrient Supplementation and Neuro Development: Timing is The Key. Arch. Pediatr. Adolesc. Med. 166, 481-482. 
Darmadi. (2008). Penyakit Infeksi Nosokomial. Jakarta : Salemba Medika.

de Onis, M., \& Branca, F. (2016). Childhood Stunting: A Global Perspective. Maternal and Child Nutrition, 12 (1), 12-26. https://doi.org/10.1111/mcn.12231.

Dinas Kesehatan Provinsi Bengkulu. (2015). Hasil Survei Pemantauan Status Gizi Provinsi Bengkulu Tahun 2015. Bengkulu : Dinas Kesehatan Provinsi Bengkulu.

Dinas Kesehatan Kota Bengkulu. (2014). Hasil Pemantauan Status Gizi (PSG) di Kota Bengkulu Tahun 2014 Menurut Indeks TB/U. Bengkulu : Dinas Kesehatan Kota Bengkulu.

Departemen Kesehatan RI. (2008). Riset Kesehatan Dasar (RISKESDAS) 2007. Jakarta : Departemen Kesehatan RI. Retrieved from: kesga.kemkes.go.id/images/pedoma n/Riskesdas\%202007\%20Nasional. pdf.

Fajariyah, R. N., \& Hidajah, A. C. (2020). Hubungan Kejadian Stunting dengan Status Imunisasi dan Tinggi Ibu pada Anak Usia 2-5 Tahun di Indonesia. Jurnal Berkala Epidemiologi. 8 (1) : 89-96.

Kasim, E., Malonda, N., \& Amisi, M. (2019). Hubungan antara Riwayat Pemberian Imunisasi dan Penyakit Infeksi dengan Status Gizi pada Anak Usia 24-59 Bulan di Kecamatan Ratahan Kabupaten Minahasa Tenggara. Jurnal Bios Logos. 9 (1) : 34-43.

Kementerian Kesehatan RI. (2013). Riset Kesehatan Dasar (Riskesdas) 2013. Jakarta: Kementerian Kesehatan RI. Retrieved from Http://www.depkes.go.id/resources/ download/general/Hasil\%20Riskesd as\%202013.pdf.

Kementerian Kesehatan RI. (2010). Riset Kesehatan Dasar (RISKESDAS) 2010. Jakarta : Kementerian
Kesehatan RI. Retrieved from: kesga.kemkes.go.id/images/pedoma n/Riskesdas\%202010\%20Nasional. pdf.

Mishra, M., Singh, R., Dwivedi, S., Hassan, M.A., Praveen, K., \& Khan, M.A. (2015). Association of Feeding Practices and Immunization with Nutritional Status of Infants in Jasra Block of Allahabad District. Indian Journal Child Health. 2 (2) : 72-75. Stewart, C. P., Iannotti, L., Dewey, K. G., Michaelsen, K. F., \& Onyango, A. W. (2013). Contextualising Complementary Feeding in A Broader Framework for Stunting. Prevention. Maternal \& Child Nutrition. 9, 27-45. Https://doi.org/10.1111/mcn.12088

Swathma, D., Lestari, S., \& Ardiansyah, R. T. (2016). Analisis Faktor Risiko BBLR, Panjang Badan Bayi Saat Lahir, dan Kejadian Stunting pada Balita di Wilayah Kerja Puskesmas Kota Kandai. Jurnal Ilmiah Kesehatan Masyarakat, 1 (3) : 1-10.

WHO. (2020). WHA Global Nutrition Targets 2025: Stunting Policy Brief. Geneva : WHO. Retrieved from: Https://www.who.int/nutrition/topic s/globaltargets_stunting_policybrief .pdf.

WHO. (1997). WHO Global Database on Child Growth and Malnutrition. Geneva : WHO. 